\title{
Workplace based assessment by Direct Observation of procedural skills for postgraduate students in Obstetrics and Gynaecology
}

\author{
Dabhadkar, S. ${ }^{1}$, Panchanadikar, $T .{ }^{2}$, Nimbargi, . $^{3}$ \& Taralekar, $V^{4}$
}

\begin{abstract}
Introduction: Structured workplace based assessment in PG curriculum is the need of the hour. This project addresses the same. This study was conducted to assess procedural skill of postgraduate students by using a novel tool-Direct Observation of Procedural skills (DOPS) and impact on learning by reassessment.
\end{abstract}

Methodology: Seven second year postgraduate students and eight faculty members participated in the study. First DOPS cycle was conducted over 6 weeks for 5 basic procedures in Obstetrics and Gynecology (OBGY). The checklists of procedures were shared. Second DOPS cycle was conducted by same faculty. At the end, feedback about the entire process was collected and analyzed.

Results: All the students showed improvement in DOPS scores during second session. The component task wise score analysis showed statistically significant improvement in following areas such as maintenance of asepsis, pre procedure preparations, demonstration of anatomy and indications, communication with patient, post procedure management and overall tissue handling. This was evident when 'paired $t$ test' was applied to the data. Analysis of feedback showed acceptability, feasibility and relevance of DOPS in OBGY.

Conclusion: We found that DOPS is highly acceptable assessment tool by both the postgraduate students and faculty. It helped students to identify gaps in learning and achieve improvement in skills.

Key words: Workplace based assessment, Skill teaching in Obstetrics and Gynecology, Direct Observation.

\section{Introduction}

Postgraduate training in medical education is focused on performance in actual clinical situations. Developing methods for assessing performance is a universal challenge. There are various 'work place based assessment tools' in medical education described in the literature.

\footnotetext{
${ }^{1}$ Associate Professor, Department of OBGY, Bharati Vidyapeeth Medical College, Pune

2, ${ }^{284}$ Professor, Department of OBGY, Bharati Vidyapeeth Medical College, Pune

Corresponding Author:

Suchita Dabhadkar

Associate Professor, Department of OBGY, Bharati Vidyapeeth Medical College, Pune

E mail: sdabhadkar9@gmail.com
}

The Postgraduate Medical Education and Training Board, UK defines Work Place Based Assessment (WPBA) as the assessment of working practices based on what doctors actually do in a clinical setting, predominantly carried out in the workplace itself (WBPA guide 2016).

Three important components of WPBA are 'Direct Observation', 'Done in workplace' and 'feedback for improvement'. WPBA is being increasingly used to assess the trainees by direct observation and to shape their learning in developed countries. These kind of formative assessments are good for in course training. WPBA addresses the assessment of performance, the highest level in Miller's pyramid (Singh \& Modi, 2013).

DOI: http://doi.org/10.4038/seajme.v13i1.62

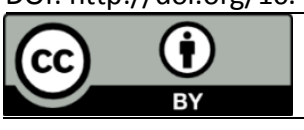

46 
Traditionally in India, assessment in postgraduate medical education revolves around summative examination. These summative examinations fail to address the assessment of skills and performance. If we consider the vision 2015 document of $\mathrm{MCl}$ and envision the better development of competencies in an Indian medical postgraduate, we have to match our assessment methods to various steps of competency building and skills development (MCl Booklet, 2016).

A postgraduate trainee in the Department of OBGY at our institute is expected to achieve different competencies at various levels of training. They learn from various sources like near peers, lecturers and other staff members.

Currently, there is a lack of systematic assessment of their performance during the course. These students are assessed randomly through daily clinical rounds and their presentations in the department. There is no scope for giving constructive, individual feedback in these situations. Neither is there any formal assessment of the psychomotor skills or soft skills. Direct Observation of Procedural Skills (DOPS) is one of the WPBA methods which can address this gap in the teaching learning program.

We carried out a pilot project to evaluate DOPS in OBGY with a single module "examination of female genital tract' in 2013 (Dabhadkar et al., 2014). It had shown significant improvements in aseptic precautions and communication skills of the postgraduate students.

This project was planned to extend the same study including more clinical procedures carried out routinely by the postgraduate students in OBGY.

\section{Objectives}

Following were the objectives identified for the study:

1. To assess procedural skills of second year postgraduate students by using DOPS.

2. To give constructive feedback to these postgraduate students about procedural skills and soft skills.

3. To assess impact on learning by reassessment after 4-6 weeks of practice.

\section{Methods}

This prospective interventional study was planned at our institute. Participants were
OBGY faculty (8), second year PG students (7) and patients. Institutional Ethics committee approval was taken for the study. Study was conducted in following phases:

\section{Step 1: Planning and preparation}

All faculty members and postgraduate students from Department of OBGY were sensitized about the new assessment method: DOPS by using a short lecture and YouTube video. Session about giving effective feedback was arranged for OBGY faculty. Standard Operative Procedure for the core skills enlisted below was prepared by group discussion in the Department.

- Perform per speculum and per vaginal examination

- Perform a Papanicolau cervical smear

- Intrauterine contraceptive device insertion

- Plotting Partogram in first stage of labour

- Giving IV MgSO4 in cases of severe preEclampsia

A revalidated scale for DOPS Evaluation was designed, peer reviewed and piloted. Formats for taking feedback about the entire procedure from all participants were prepared.

\section{Step 2: Execution}

Informed written consent of all participants was taken. Individual folders were created for each student containing the DOPS evaluation score sheet. The procedural feedback form (for observer feedback) was also added in the same folder. These folders were handed over to all the 7 students.

The students were asked to approach different faculty members to carry out the 1st DOPS cycle for the 5 identified skills. Each assessment session took around 20 minutes. It was followed by 7-8 minutes of observer feedback to the PG student. Faculty observed the procedure and gave scores using the standard revalidated DOPS global score sheet. The students returned the folders after they finished with the observation of all five skills. 1st DOPS cycle was conducted over 6 weeks' time frame.

A session was conducted to debrief the process of DOPS with the students. The standard checklist about each procedure was shared and discussed with the students. Students were given an opportunity to practice the skills for four to six weeks. After this period, second 
cycle was planned over the next 6 weeks. New set of individual folders were created for each student containing the DOPS evaluation score sheet. The procedural feedback form (for observer feedback) was also added in the same folder. These folders were handed over to all 7 students.

Students were asked to approach the same faculty for the same procedure during second DOPS cycle. The students returned the folders after they finished with the observation of all five skills. Written feedback about the entire experience was taken from students and the faculty members. Structured and open ended questions were used for capturing effective feedback.

\section{Step 3: Analysis and documentation}

Data collected through the DOPS Score sheets after first and second cycle was compared and analyzed. Feedback forms collected from the students and faculty members were also analyzed.

\section{Results}

DOPS scores from cycle 1 and cycle 2 were analyzed to compare competency level of the students. Feedback forms from all participants were analyzed to evaluate this intervention.
Figure 1 shows percentage of DOPS scores for all 5 identified procedures during 1st DOPS cycle. Each procedure was scored by Revalidated DOPS score sheet. Each skill was further broken in following 9 component tasks.

- Demonstration of Anatomy and Indication for the procedure

- Communication with patient

- Obtaining consent from patient

- Pre procedure preparation

- Technical Ability

- Maintenance of asepsis

- Post procedure management

- Tissue handling and patient comfort

- Ask for help

Each task was graded with scores as below:

- Not done: 0

- Below expectation: 1

- Meets expectation: 2

- Above expectation: 3

The score given for technical ability was doubled for calculation to highlight the importance of specific demonstration of technical ability for each procedure. Each skill was assigned maximum 30 marks. Score above $60 \%$ was considered satisfactory for each individual procedure.

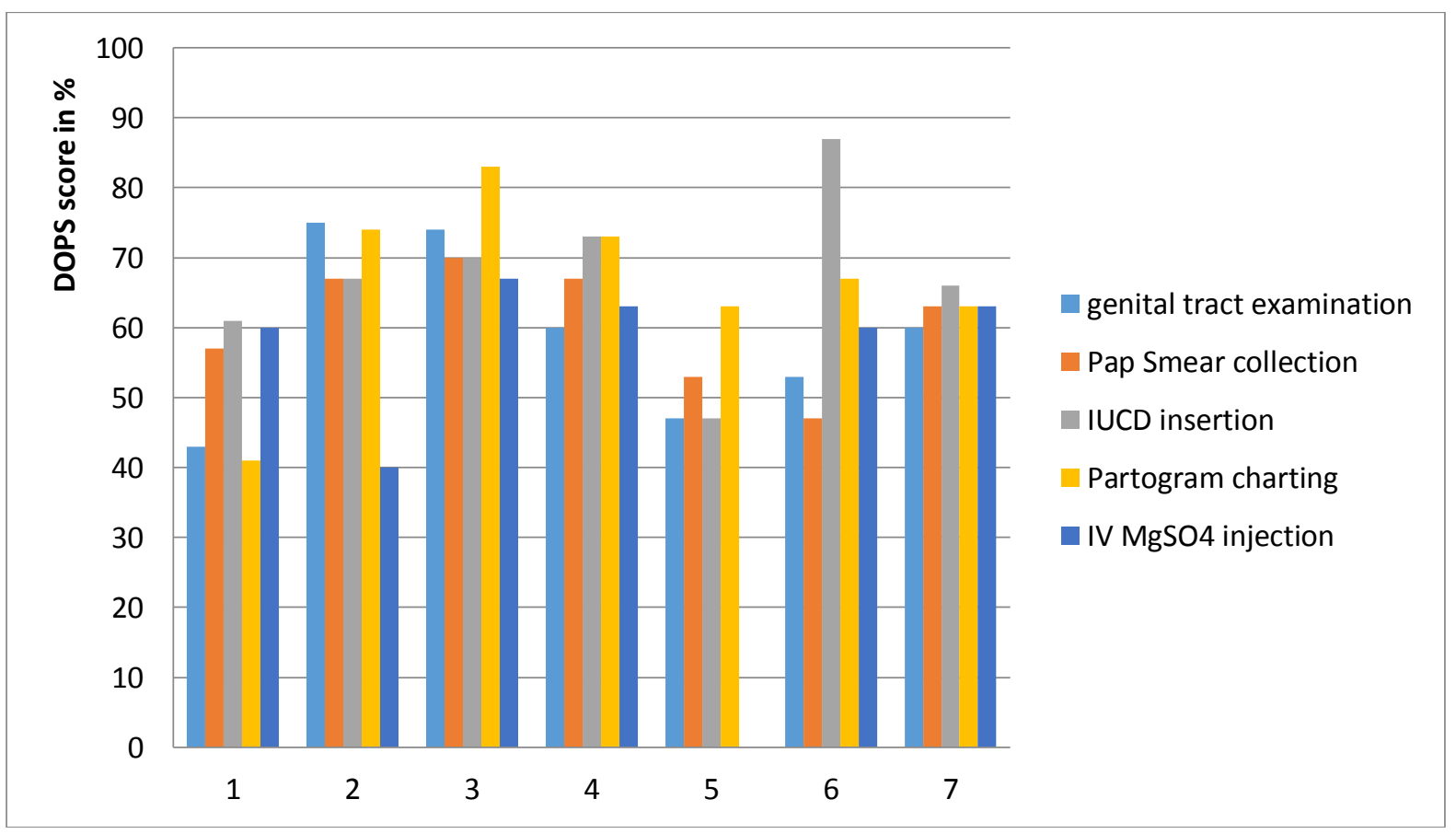

Figure 1: Students DOPS Scores in first cycle in all five procedures 
Figure 2 shows percentage of DOPS scores for all 5 identified procedures during 2nd DOPS cycle. After completion of DOPS cycle 1 , the checklists were shared with all students for each identified procedure. After a gap of around
4 weeks, students were asked to undergo second DOPS cycle with the same faculty for all 5 procedures. Every student could perform all procedures to the satisfaction level during second DOPS cycle.

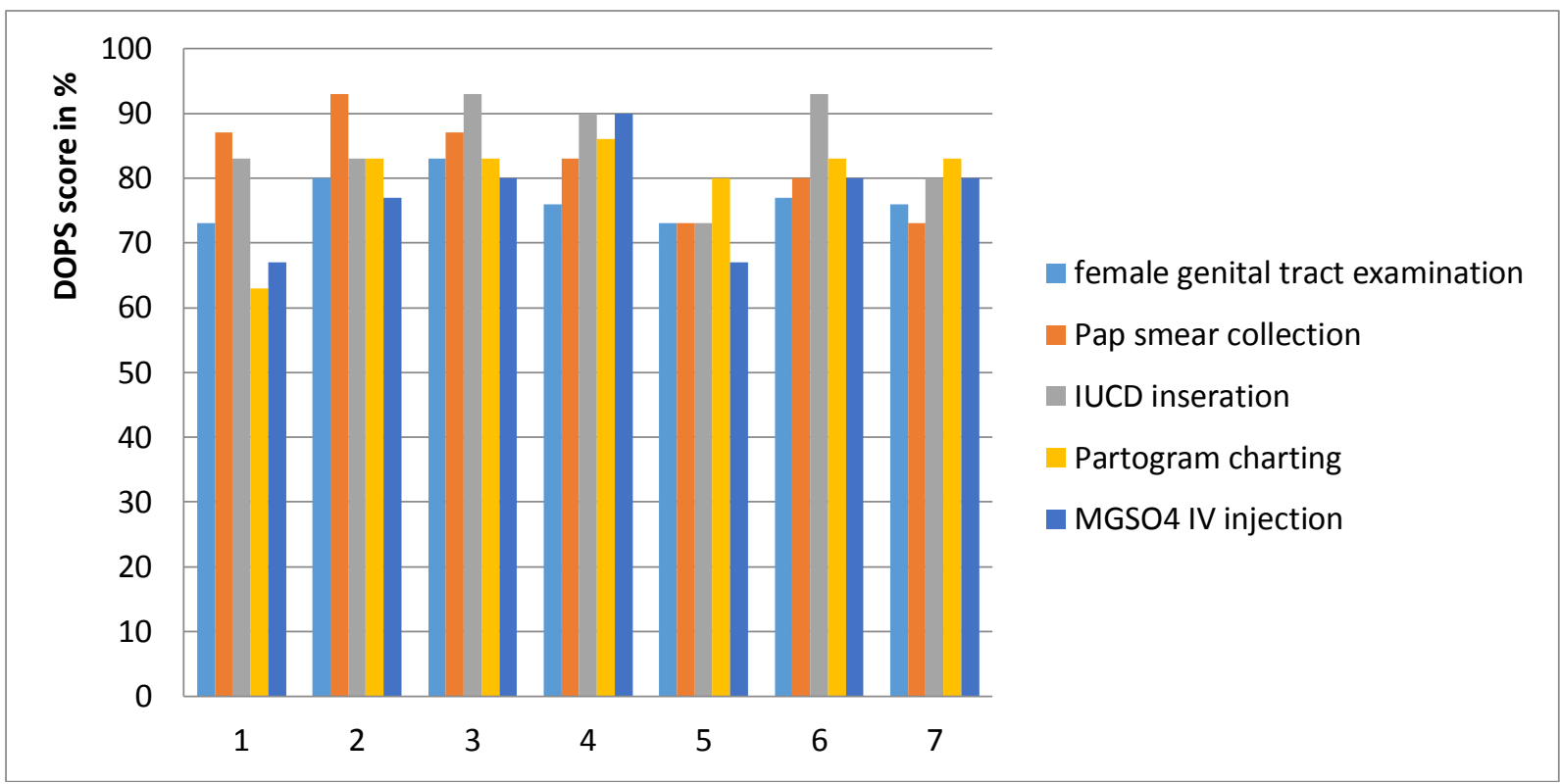

Figure 2: Students DOPS Scores in second cycle in all five procedures

Table 1 shows the detailed comparative component task wise scores for all 5 procedures of each student. Eight out of nine component tasks remain the common subskill set necessary for carrying out any successful clinical procedure. The scores were combined for each component task, except specific technical ability. The 2nd DOPs cycle was conducted after 4 weeks of gap, during which students practiced with the checklist. Table 2 shows statistical analysis of task wise scores across 2 DOPs cycles. It was compared and analyzed using MS Excel.

Table 1: Component task wise scores for 2 cycles

\begin{tabular}{|c|c|c|c|c|c|c|c|c|c|c|c|c|c|c|}
\hline \multirow[t]{2}{*}{ Students } & \multicolumn{2}{|c|}{$\begin{array}{c}\text { Anatomy } \\
\text { Understanding }\end{array}$} & \multicolumn{2}{|c|}{$\begin{array}{l}\text { Communic } \\
\text { ation skills }\end{array}$} & \multicolumn{2}{|c|}{ Consent } & \multicolumn{2}{|c|}{$\begin{array}{c}\text { Pre } \\
\text { procedure } \\
\text { preparation }\end{array}$} & \multicolumn{2}{|c|}{$\begin{array}{l}\text { Maintenance } \\
\text { of asepsis }\end{array}$} & \multicolumn{2}{|c|}{$\begin{array}{c}\text { Pre } \\
\text { procedure } \\
\text { preparation }\end{array}$} & \multicolumn{2}{|c|}{$\begin{array}{c}\text { Tissue } \\
\text { handling }\end{array}$} \\
\hline & $1^{\text {st }}$ & $2^{\text {nd }}$ & $1^{\text {st }}$ & $2^{\text {nd }}$ & $1^{\text {st }}$ & $2^{\text {nd }}$ & $1^{\text {st }}$ & $2^{\text {nd }}$ & $1^{\text {st }}$ & $2^{\text {nd }}$ & $1^{\text {st }}$ & $2^{\text {nd }}$ & $1^{\text {st }}$ & $2^{\text {nd }}$ \\
\hline 1 & 10 & 11 & 6 & 12 & 9 & 11 & 6 & 11 & 9 & 11 & 9 & 11 & 8 & 10 \\
\hline 2 & 9 & 11 & 13 & 14 & 12 & 12 & 10 & 14 & 11 & 13 & 7 & 14 & 7 & 11 \\
\hline 3 & 11 & 12 & 14 & 14 & 8 & 14 & 10 & 14 & 10 & 14 & 10 & 13 & 8 & 13 \\
\hline 4 & 11 & 13 & 10 & 14 & 10 & 12 & 9 & 15 & 9 & 11 & 9 & 14 & 11 & 12 \\
\hline 5 & 7 & 9 & 6 & 10 & 9 & 11 & 6 & 9 & 7 & 10 & 6 & 89 & 5 & 9 \\
\hline 6 & 10 & 12 & 9 & 13 & 10 & 12 & 7 & 12 & 10 & 14 & 7 & 10 & 10 & 11 \\
\hline 7 & 13 & 13 & 7 & 13 & 11 & 12 & 8 & 13 & 9 & 13 & 10 & 14 & 9 & 10 \\
\hline
\end{tabular}


Table 2: Paired sample test analysis of component taskwise scores for all 7 students

\begin{tabular}{|c|c|c|c|c|c|c|c|c|c|}
\hline & & \multicolumn{5}{|c|}{ Paired Differences } & \multirow{3}{*}{$\mathbf{t}$} & \multirow{3}{*}{ df } & \multirow{3}{*}{$\begin{array}{l}\text { Sig. } \\
(2- \\
\text { tailed) }\end{array}$} \\
\hline \multirow{2}{*}{\multicolumn{2}{|c|}{ Student pairs }} & \multirow[t]{2}{*}{ Mean } & \multirow[t]{2}{*}{$\begin{array}{c}\text { Std. } \\
\text { Deviation }\end{array}$} & \multirow[t]{2}{*}{$\begin{array}{l}\text { Std. } \\
\text { Error } \\
\text { Mean }\end{array}$} & \multicolumn{2}{|c|}{$\begin{array}{l}\text { 95\% Confidence } \\
\text { Interval of the } \\
\text { Difference }\end{array}$} & & & \\
\hline & & & & & Lower & Upper & & & \\
\hline Pair 1 & $\begin{array}{l}\text { @1_anatomy } \\
\text { @2_anatomy }\end{array}$ & -1.4286 & 0.7868 & 0.2974 & -2.1562 & -0.7009 & -4.804 & 6 & 0.003 \\
\hline Pair 2 & $\begin{array}{l}@ 1 \text { @_com } \\
@ 2 \text { com }\end{array}$ & -3.5714 & 2.2991 & 0.869 & -5.6977 & -1.4451 & -4.11 & 6 & 0.006 \\
\hline Pair 3 & $\begin{array}{l}\text { @1_consent } \\
\text { @2_consent }\end{array}$ & -2.1429 & 1.8645 & 0.7047 & -3.8672 & -0.4185 & -3.041 & 6 & 0.023 \\
\hline Pair 4 & $\begin{array}{l}\text { @1_prepare } \\
\text { 2_prepare }\end{array}$ & -4.5714 & 0.9759 & 0.3689 & -5.474 & -3.6689 & -12.394 & 6 & 0 \\
\hline Pair 5 & $\begin{array}{l}\text { @1_asepsis } \\
\text { 2_asepsis }\end{array}$ & -3 & 1 & 0.378 & -3.9248 & -2.0752 & -7.937 & 6 & 0 \\
\hline Pair 6 & $\begin{array}{l}\text { @1_postpro } \\
\text { 2_postpro }\end{array}$ & -3.7143 & 1.7995 & 0.6801 & -5.3785 & -2.0501 & -5.461 & 6 & 0.002 \\
\hline Pair 7 & $\begin{array}{l}\text { @1_tissue } \\
@ 2 \text { tissue }\end{array}$ & -2.5714 & 1.7182 & 0.6494 & -4.1605 & -0.9823 & -3.959 & 6 & 0.007 \\
\hline Pair 8 & $\begin{array}{l}\text { @1_help } \\
@ 2 \text { help }\end{array}$ & -1.8571 & 1.4639 & 0.5533 & -3.211 & -0.5033 & -3.357 & 6 & 0.015 \\
\hline
\end{tabular}

\section{Evaluation of participant's feedback}

\section{Students' perception}

Question 1: On the scale of 0 to 5 , how well did you like the experience of participating in DOPS?

All the students liked the experience of DOPS.

Question 2: What did you like / not like about the process of DOPS? Share minimum two points.

Six out of seven students mentioned that receiving upfront feedback at the end of the procedure was a most appreciable point for them. The students liked the concept of having a structured checklist for each procedure for learning and assessment.

Question 3: Did you feel improvement in your skills while doing the procedure in the second DOPS session? All the students answered affirmatively.

Question 4: what exactly was the difference while doing the procedure the second time?

All students mentioned that they became more aware about the need for communication with patient and were careful about aseptic precautions during second DOPS cycle. This helped them to perform with more confidence. One student said that she performed the procedure with more 'mindfulness' and scored better in the second DOPS cycle.
Question 5: What were the challenges faced while arranging for DOPS?

Challenges quoted by students were time constraint in the OPD, unavailability of faculty. One of the students could not perform IV MgSO4 injection as opportunity was not available in that time frame. Arranging second DOPS cycle with same faculty was the most difficult part.

Question 6 and 7: Would you like to have DOPS conducted for other procedural skills? YES / NO If yes, name any two procedures you would like to include.

All the students expressed that assessment like DOPS should become a regular affair throughout the year. Few of the procedures mentioned were: conducting vaginal delivery, instrumental delivery, suturing of episiotomy, neonatal resuscitation etc.

\section{Faculty Perception}

Question 1: Please mark your rating for following characteristics of DOPS method using the scale below. Your responses should be based on your perception:

$\begin{array}{ll}\text { 1. } & \text { Strongly agree } \\ \text { 2. } & \text { Agree } \\ \text { 3. } & \text { Neither } \\ \text { 4. } & \text { Disagree } \\ \text { 5. } & \text { Strongly disagree }\end{array}$




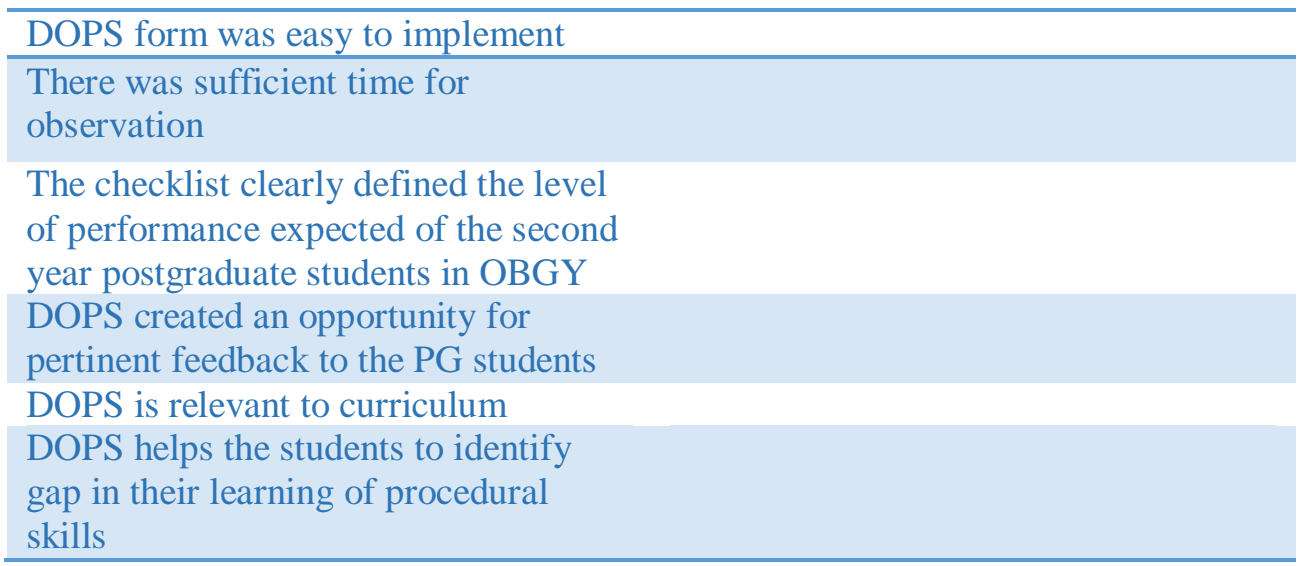

Figure 3: The scale to mark the ratings

Question 2: Please elaborate your response by mentioning minimum two points about this assessment method.

All of the 8 participating faculty agreed that DOPS is relevant to curriculum. All of the faculties felt that there was sufficient time for observation of students performing the skills in wards. $50 \%$ faculty mentioned busy OPD hours, additional academic activities as challenges for DOPS. All of them agreed that the checklist was helpful and self-explanatory, clearly defined level of performance expected of the second year postgraduate student in OBGY. All of them agreed that DOPS helps the students to identify gap in their learning of procedural skills.

Question3: Would you like to incorporate DOPS as a regular formative assessment tool in OBGY PG curriculum? Yes/no (Give Reason). All of them expressed that it should be incorporated as regular assessment tool. 6 out of 8 faculty members felt that preparing checklists for every procedure will be very time consuming and lot of efforts will be needed. The faculty expressed that there was remarkable improvement in communication, aseptic precautions as well as pre and post procedure management by every participating student. One faculty mentioned that more training of teachers is needed for conducting these types of assessments.

\section{Discussion}

Postgraduate studies are aimed at moving from lower levels of Miller's pyramid to reach the apex. From being a novice one becomes an expert. To become an expert, same skill has to be practiced repeatedly. If you practice wrong things repeatedly, you become 'experienced in expert' (Kogan et al., 2009).
Without proper feedback and opportunity of implementing changes, random in training observations fail to address the student's learning needs and progress (Kundra \& Singh, 2014). To bridge this gap we planned this curriculum innovation project. Developing faculty awareness for this project was achieved by arranging a didactic lecture on assessment tools, showing a YouTube video on DOPS and effective feedback session by one of our medical faculty. Emphasis was given on giving effective feedback at the end of the procedure.

The most noticeable thing about initial sessions of DOPS was palpable excitement of the students. Students took extra efforts in finding out the opportunity and arranging for faculty across all units. Despite this one student could not arrange for IV MgSO4 injection session during first DOPS cycle. Finding opportunity for a given task and managing faculty was the biggest challenge. WPBA have these universal constraints as shown by previous studies (Beard et al., 2005).

The feedback process helped the students to think about their own strengths and weakness in performing the procedures. Previous studies have shown similar effects of formal assessment and feedback on physician performance (Norcini \& Burch, 2007; Van Der Vleuten \& Schuwirth, 2005).

It is evident from Table 1 that though the skills chosen were basic procedures done by second year postgraduate students in OBGY 3 out of 7 students were below expectation in 2-3 procedures. The component task wise score analysis showed most neglected areas were effective communication with patient, maintaining asepsis and pre procedural preparations. 
All the students showed improvement in DOPS scores during second cycle. Statistically significant improvement was observed in following areas:

1. Maintenance of asepsis

2. Pre procedure preparations

3. Demonstration of anatomy and indications

4. Communication with patient

5. Post procedure management

6. Overall tissue handling

This was evident when paired t test was applied to the data collected under each component task in first and second DOPS session. There was overall improvement in confidence and competence level of students as expressed by the students as well as 5 out of 8 faculty members in their feedback. This finding is consistent with previous studies from India (Kundra \& Singh, 2015).

\section{Limitations}

As mentioned earlier one student could not arrange for IV MgSO4 session in first DOPS. During second DOPS session 5 procedures were observed by different faculty members. Still we considered them for analysis. Scores were consistent. May be this shows that faculty training was adequate and there was less inter observer bias.

\section{Conclusion}

DOPS proved to be very well acceptable WPBA tool by both the postgraduate students as well as faculty in OBGY. Everyone expressed that having such an objective tool for performance assessment is the need of the hour. Practicing with checklist and receiving individual feedback helped the students identify the gaps in their learning. The paired t test showed remarkable improvement in students' clinical skills and soft skills. We recommend incorporating DOPS in $P G$ curriculum in OBGY. This will definitely help the patients at large to receive better clinical care.

\section{Acknowledgement}

I acknowledge the OBGY faculty, enthusiastic students, patients and ME faculty for making this project successful.

\section{References}

Beard, J.D., Jolly, B.C., Newble, D.I., Thomas, W.E.G., Donnelly, J. \& Southgate, L.J. (2005) Assessing the technical skills of surgical trainees, British Journal of Surgery: Incorporating European Journal of Surgery and Swiss Surgery, 92, 6, pp. 778-782

Dabhadkar, S., Wagh, G., Panchanadikar, T., Mehendale, S. \& Saoji, V. (2014) To evaluate Direct Observation of Procedural Skills in OBGY, National Journal of Integrated Research in Medicine, 5, 3

Fromme, H.B., Karani, R. \& Downing, S.M. (2009) Direct observation in medical education: a review of the literature and evidence for validity, Mount Sinai Journal of Medicine: A Journal of Translational and Personalized Medicine: $A$ Journal of Translational and Personalized Medicine, 76, 4, pp. 365-371

Kogan, J.R., Holmboe, E.S. \& Hauer, K.E. (2009) Tools for direct observation and assessment of clinical skills of medical trainees: a systematic review, JAMA, 302, 12, pp. 1316-1326

http://www.mciindia.org/tools/announcement/MCl_b ooklet.pdf (accessed on 25 Dec 2016)

Norcini, J. \& Burch, V. (2007) Workplace-based assessment as an educational tool: AMEE Guide No. 31, Medical teacher, 29, 9-10, pp. 855-871

Kundra, S. \& Singh, T. (2014) Feasibility and acceptability of direct observation of procedural skills to improve procedural skills, Indian Pediatrics, 51, 1, pp. 59-60

Singh, T. \& Modi, J.N. (2013) Workplace-based assessment: A step to promote competency based postgraduate training, Indian pediatrics, 50,6 , pp. 553-559

http://www.gmcuk.org/Workplace_Based_Assessm ent A guide_for_implementation_0410.pdf 48905168.pdf (accessed on 25 Dec 2016)

Van Der Vleuten, C.P. \& Schuwirth, L.W. (2005) Assessing professional competence: from methods to programmes, Medical education, 39, 3, pp. 309-317 